\title{
Assessment of Dealers' Contribution in Current and Future E-waste Management Trends Within Dar es Salaam, Tanzania
}

\author{
Nyabise Nelson $^{1 *}$, Niu Dongjie ${ }^{2}$, Petro Mwamlima ${ }^{3}$ and \\ Samson Mwitalemi ${ }^{4}$
}

\begin{abstract}
${ }^{1}$ UNEP-Tongji Institute of Environment for Sustainable Development (IESD), College of Environmental Science and Engineering, Tongji University, Shanghai 200092, China
\end{abstract}

${ }^{2}$ Shanghai Institute of Pollution Control and Ecological Security; State Key Laboratory of Pollution Control and Resources Reuse; Key Laboratory of Yangtze River Water Environment, Ministry of Education, Tongji University, Siping Rd 1239, Shanghai,200092, People Republic of China

3Department of Environmental Science and Management, School of Environmental Science andTechnology, Ardhi University, P.O. Box 35176, Dar es Salaam, Tanzania

${ }^{4}$ Principled Entrepreneurship and Innovations (PEI Enterprises), Opposite to Njiapanda ya Chuo, P.O. Box 34234, Dar es Salaam, Tanzania

E-mail: nnyabise@gmail.com; niudongie@tongji.edu.cn; g.peyam@gmail.com; sammbwasi@gmail.com

*Corresponding author: Nyabise Nelson; nnyabise@gmail.com

\begin{abstract}
Dar es Salaam city, generates massive amount of Waste Electrical and Electronic Equipments (WEEE) that either ends up in the environment or kept at home or commercial areas. This study aimed at investigating the currenting WEEE management practices, assessing the level of public awareness on WEEE, and come up with the model that can predict the rate (\%) of discarded WEEE. Both the qualitative and qualitative methods of data collection were used, that is the use of questionnaires, and interviews to EEE business people, repair technicians, public, recycling companies and the regulating authority. It was found out that Increase in WEEE within Dar es Salaam city is caused by growth of economic rate, population growth rate, household purchasing capacity, while the decrease of the waste is associated with recycling plans and exportation of the waste. Also, the public (76\%) doesn't consider the broken or expired EEE as waste, as a result they opt to keep them at home than giving them to recyclers or collectors. Even though there are recyclers within the city, they can only recycle $35 \%$ of the generated WEEE. If the current situation continues by 2026 , about $68 \%$ of the generated WEEE will be discarded to the environment or at home or business places. The situation shall be rectified by promoting the WEEE recyclers.
\end{abstract}

Keyword: Electrical and Electronic Equipments (E-Equipments); Waste Electronic and Electrical Equipments (WEEE); Waste Electronic; Electrical Equipments management (WEEE management);Dealers

\section{HIGHLIGHTS}

- This study investigated the role of dealers in determination of current and predicting the future management trends of WEEE within Dar es City, Tanzania.

- The study utilized both the quantitative and qualitative methods of Data collection, including the questionnaires, Key informant interviews and the review of both Peer review and grey literatures (working reports).

- Dar es Salaam city was selected as a case study to represent alike cities in developing countries, because it is among the fast-growing city within Africa.

- The study found out that Civilians of Dar es Salaam city have an average household purchasing capacity of EEE of 36\%, where by all residents have necessary EEE like phones. Yet, these generators of WEEE opt to keep their waste at home because they don't have a culture of giving them away or selling them to WEEE collectors. As a result, a significant amount of generated WEEE is predicted to not be collected, and handled properly (recycled/re-used).

- The study concluded that WEEE is expected to increase and outweigh the current management interventions. As a result, it was recommended that the Ministry of vice presidents, environmental division should reduce the registration costs and the bureaucracy for more WEEE recycling companies to join the business. 


\section{INTRODUCTION}

Waste Electronic and Electrical Equipments (WEEE) is referred to as the materials or leftovers generated form the use of electrical and electronic equipments, without any intention of re-using or recycling them. The increased use of information and communication technologies is termed as one of the major contributors to WEEE, followed by other domestic and commercial electrical and electronic equipments $[1,4,5,6,45]$. The generation of WEEE is associated with population growth rate, whereby the as population increase the demand for the Electrical and Electronic Equipments (EEE) is also expected to increase as a result the volume of WEEE will increase, also the raise in economic status of both the; heads of families, city and nation triggers the demand for EEE, that eventually will lead to more generation of WEEE $[1,2,41,42,43]$.

Dar es Salaam city, the business hub of Tanzania, has a population growth rate of $5.6 \%$ and an economic growth rate of $7 \%[12,13]$. This fast-growing city of Africa is thought to generate massive amount of WEEE that contributes significantly to an estimated WEEE generation rate of 35,000 metric tons country wise [11]. There are available recycling and re-use options that are considered as safe practice world-wide, among others is the refurbishment technology where the manufacturer takes trouble of refurbishing the used or destroyed equipment by replacing the destroyed parts with the new one and re-sell the equipment as a refurbished. The process is done in closed environment where the public is protected from all the harms that may arise $[3,35,43]$.
These modern technologies are not available in Tanzania. That being the case waste generation increases especially in cities with high population like Dar es Salaam $[11,36,37$, $38,39,40]$.

Researches has been done by several researchers to assess the adequate treatment of some WEEE, yet there is less information covered in Tanzania and Africa at large, especially in fast growing cities like Dar es Salaam city. This study is therefore intending to fill the gap, by studying the currenting WEEE management practices, assessing the level of public awareness on the adequate management practices of WEEE within the city and finally come with the model that can predict the rate (\%) of discarded WEEE to the environment or at homes.

\section{METHODS}

\section{Description of Study Area}

This study was conducted in Dar es Salaam, Tanzania (FIGURE 1). Dar es Salaam is the largest city and economic hub of Tanzania located along the coast of Indian Ocean, with an annual population growth rate of 5.6\% [13]. The city has total area $1393 \mathrm{~km}^{2}$ and is estimated to have an economic growth rate of $7 \%$ [12]. This study explored the potential generators of e-wastes from Kariakoo, households at Kariakoo and Karume streets. The two streets were selected because they represent the major business part of the city (Kariakoo and Karume market) where electronic materials are sold and repaired. Furthermore, the study explored the potential dealers involved in collection, storage, transportation and recycling of e-wastes, within the city.

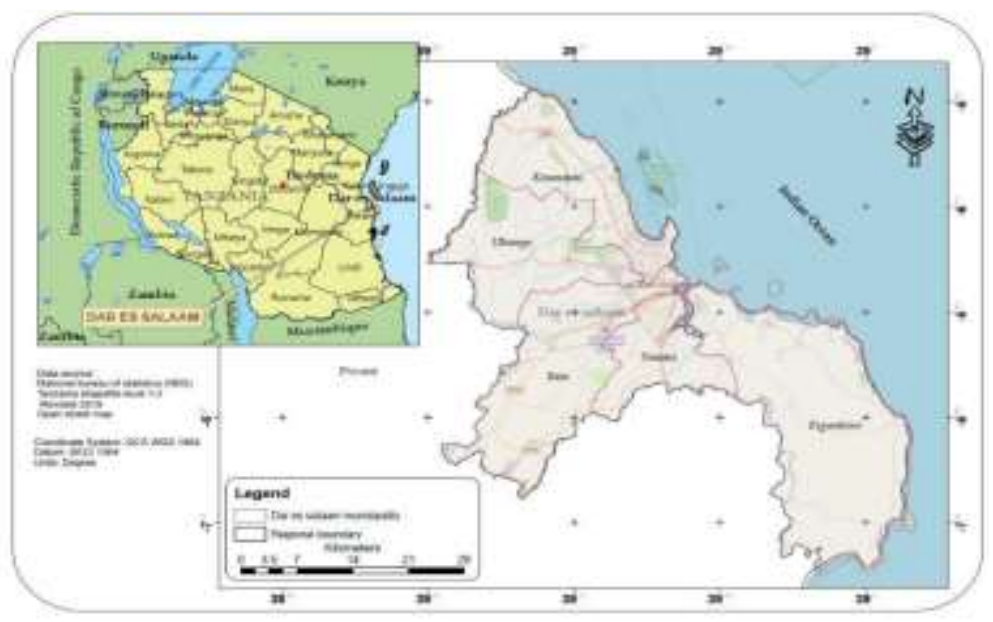

FIGURE 1: Location of the case study (Modified from Ramani Huria shapefiles, 2012)

\section{Study design}

The study utilized both the quantitative and qualitative methods of data collections. Whereby, the quantitative data was employed in collecting data using questionnaires. The questionnaires were structured to respond to required information on identification and analysis of dealers involved in e-waste management, the current and future waste trends and the evaluation of level of public awareness on e-waste management. On the other hand, the qualitative methods that included; key informant interviews to recyclers and e-waste regulators (NEMC officer) was done to obtain the forces behind current management practices and the expected future trends. Furthermore, literature review was done to gather information related to the subject matter. Both the peer reviewed and grey literatures were reviewed.

The collected data were analyzed using SPSS version 20 was used for analytical data analysis, and Microsoft excel version 2019 software together with XLSTAT version 2021 , were applied in analysis of numerical data and statistical analysis.

\section{Sample size determination}

The study population was determined by using Cochran equation (equation 1).

$$
n=\frac{Z^{2}(p)(1-p)}{c^{2}}
$$

Where:

$\mathrm{n}=$ The desired sample size

$\mathrm{z}=$ Standard normal deviation set at $95 \%$ confidence level

$\mathrm{p}=$ Percentage picking a choice or response $(0.5)$

$\mathrm{c}=$ Confidence interval $(0.05)$

About 100 EEE shop sellers out of 131 available shops at Kariakoo market were supplied with questionnaires to represent the rest. Also, about 100 households were selected to represent 129 households located near Kariakoo streets. Lastly a population of 180 EEE technicities were selected to represent a total of 340 technicians available at the market and nearby environment (Magomeni and Karume). 


\section{WEEE Dealers inventory and analysis}

Data regarding dealer's involvement in e-waste management was collected using the ArcMap version 10.7 software, whereby the potential dealers were mapped and assessed by using interview guiding questions. All the dealers (collectors and recyclers) were visited and interviewed in order to get the intended information on how they manage the e-waste. The output of this study was inventory map and management system layout. The gaps were identified to be rectified by the researcher.

\section{Level of public awareness on WEEE management in Dar} es Salaam city

The level of the public towards ways of managing e-waste and potential health and environmental hazards arising from discarded e-waste was assesses using questionnaires. Whereby respondents were required to provide information on the e-equipment they use and the management practice they use together with the potential hazards associated with the equipments they use if any. Moreover, the business personnel and technicians in e-equipments were also assessed based on the same required information by the household questionnaire. The identified gaps were clearly recorded for recommendations.

\section{Current and future trends of WEEE management in Dar es Salaam}

The current trends of e-waste management practices in Dar es Salaam city was assessed by reviewing the National ewaste statistics report of 2019, published by NBS and UNU (2019) [11]. The published information was compared with the physically collected data by the researcher, using questionnaires. The reviewed data is considered as secondary data, while the collected one is considered as primary data. The essence of collecting both data was to facilitate development of model for prediction of future trends. The future trend was determined by formulating an equation based on the driving forces for WEEE in Dar es Salaam city. These driving forces was considered as indicators or factors for the equation are; economic growth (egr) of Dar es Salaam city (7\%), population growth rate(pgr)

of Dar es Salaam (5.6\%), household purchasing capacity (hpc) of a family (\%), e-waste exportation rate (wer) (\%) and recycling rate (rr) (\%). All the indicators were calculated on annual basis. Hence the equation that predicts quantity of e-waste discarded in the environment is as in equation 2 .
$W E E_{d r}(\%)=n((e g r+p g r+h p c)-(w e r+r r))$

Whereby

WEEEdr = Annual discarded rate of Waste Electronic and Electrical Equipments

$(\%)$ egr = Anual economic growth rate of Dar es Salaam city (\%) pgr = Annual population growth rate of Dar es Salaam city (\%) hpc = Annual household purchasing capacity (\%)

wer = Annual WEEE exportation rate $(\%)$

$\mathrm{rr}=$ Annual recycling rate $(\%)$

$\mathrm{n}=$ Number of years ahead (projected time)

\section{Data analysis}

The collected analytical data were analyzed using the SPSS version 20 . On the other hand, the numerical values were analyzed using the Microsoft excel version 2019 and XLSTAT version 2021. The processed information was presented in graphs (pie-charts and histograms), and map representations.

\section{Ethical Considerations}

Before interviewing or submitting the questionnaire to respondents. They were fully informed on the purpose of the research and they were free to agree or disagree to participate. This was done in order to avoid inconveniences and collection of false information.

\section{RESULTS AND DISCUSSIONS}

\section{Waste Electrical and Electronic Equipment (WEEE)} Dealers inventory and analysis

The E-waste collectors and recyclers were identified within Dar es Salaam city. Whereby a total of seven dealers were identified and mapped. Of them one dealer (Chilambo general trade company) has two workshops one in Ilala municipal and the other one in Kisarawe district, Pwani region. The workshop at Kisarawe is considered to be the largest E-waste recycling plant of all the mapped workshops/companies, and the waste at the workshop are from Dar es Salaam city. The plant is allocated at Kisarawe district in Pwani region due to scarcity of areas in Dar es Salaam to place the facility of its size. The mapped companies (FIGURE 2) are the formal ones (registered companies). Apart from Chilambo general trading company which operated in Dar es Salaam and Kisarawe, other identified companies are; Gravitation particles Tanzania, Digital agency (T) Limited, New Tabosh G. company limited, Steelcom Limited and Zana workshop.

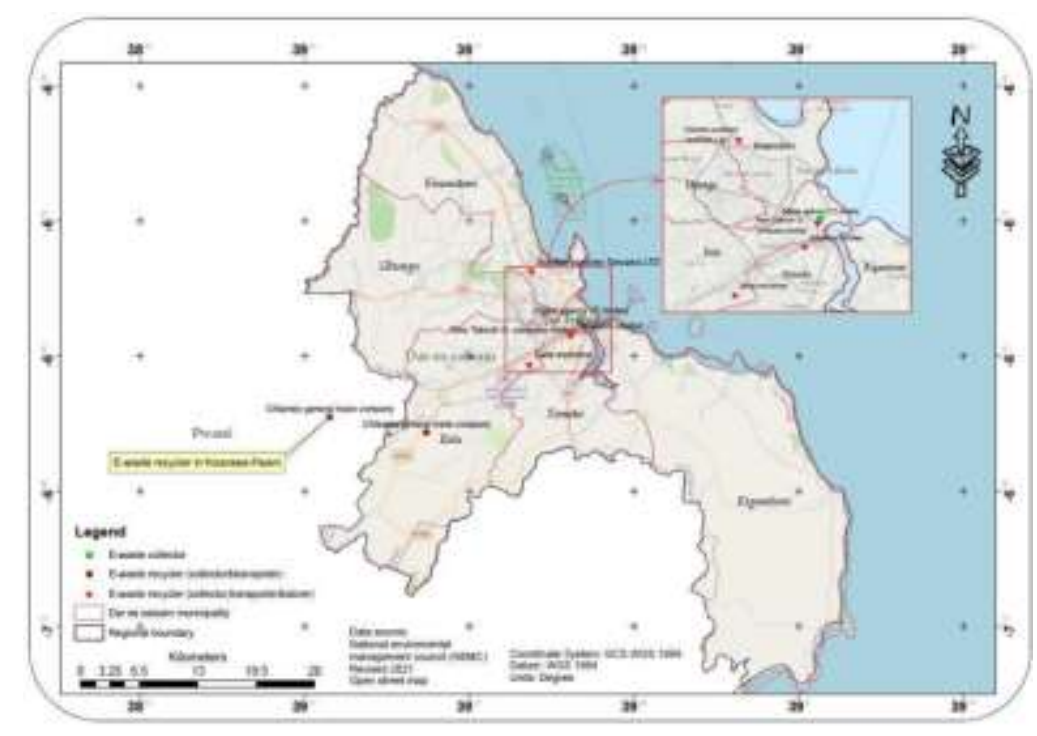

FIGURE 2: Dealers mapping involved in WEEE management 
Even though, there are quite a number of companies dealing with E-waste recycling business, yet the waste faction is not reduced significantly as only the $35 \%$ of all the generated waste within the city is cycled. The remaining fraction is either kept at home or business areas to show case the business or dumped with other solid waste at Pugu dump site or other open lands. As a result, E- resource that could be recovered is lost and also the environment and the human are harmed by the chemical compositions in the Ewaste. The chemicals in E-waste leach to water receptors that are used by humans and animals and aquatic organisms $[1,7,8,9,14,43]$. The chemicals are said to contain cancer causing heavy metals, that can stay in either soil or water for a long time.

Tanzania Recyclers Association (TARA) is an organization that aims at identifying, coordinating and supporting relevant dealers in the waste management and recycling sector. In TARA website recyclers are free to register themselves so that they can be recognized by the community and eventually be supported. But it doesn't always mean that a dealer registered by TARA is formal and legal until has been certified by the minister at the Vice-presidents Office, environmental division. Based on the interview response with an environmental engineer at National Environment

Management Council (NEMC) - Tanzania, there are very few legal E-recyclers in Dar es Salaam and Tanzania at large due to hardship in registration that is associated with high costs and bureaucracy.

The E-waste representative argued that, there are funding slots posted by TARA and other platforms to fund recyclers dealers including the E-waste, but there are many challenges preventing them from securing the funds, among other reasons reported are; Language barrier, unregistration of some dealers and whole process of applying the funds, seems to be so tough and time consuming. Also, the E-waste recycling business requires large investment for someone intending to go for large scale business, while most people involved in the business don't have, as a result they end up being small scale or just suppliers of E-waste who present themselves as recyclers. No company in Tanzania recycles the E-waste to the finished product that can be re- used but rather they process them and export them outside the country for further processing to final desired products.

More efforts are needed to support the information and communication technologies E-waste recycling, because this kind of waste occupies about $87 \%$ of the waste generated. Currently the leading EEE to be purchased is the mobile phones and its accessories, followed by Computer and accessories and lastly are the home appliances (FIGURE 3).

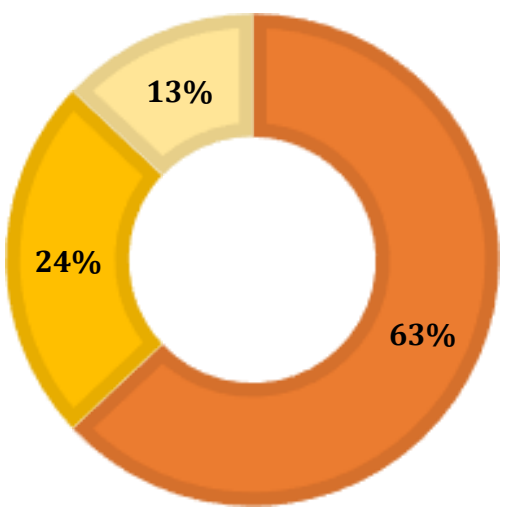

— Phones and Accessories

Computer and Accessories

$\square$ Home Appliance

The more the EEE is purchase, the more waste is expected after use and the vice versa is always true. Probably the WEEE generated will outweigh the current management interventions, that is the over relying on the Pugu landfill and small-scale recyclers. A sustainable intervention should be thought before the waste becomes a disaster within the city.

\section{Level of public awareness on WEEE management in Dar es Salaam city}

About $72 \%$ of EEE sellers in Dar es Salaam import new products but $89 \%$ of them import cheap products of fair price and fair quality, with only $11 \%$ who sell genuine (original products). On the other hand, the remaining 28\% of sellers import second hand products from china and Europe. The second-hand products come in different forms, either as reused products or republished products. Residents believe that the second-hand products are the products of high quality due to bad experience that they have on the new products they purchase. This notion comes to their mind because they compare their secondhand genuine products with the new products of low quality. Both, the fair quality new products and the secondhand products have high contribution to WEEE, as they have short life span $[21,22,23,24,25,29]$.
Dar es Salaam residents believes that the second hand (Refurbished) EEE are of better quality than the new product of similar kind and price. Their concern is built by the fact that they compare the genuine refurbished products with the fair quality new products. The residence considered price over quality, accessibility and the prior knowledge before purchasing the product as a driving main force towards purchasing the EEE (FIGURE 4). The level of education failed to separate the resediments from being moved by the price of the EEE, whereby both the educated and uneducated considered affordable price EEE as favorable EEE for use. This means that the cheap EEE have high potential of ending up to either open environment or landfill as WEEE than the expensive EEE. The accessibility and prior knowledge on the EEE were the following high scored criteria that determines the choice/selection of the EEE to be used by the residents. The quality of the products was not taken into serious consideration, the quality preferability was found to depend much on the level of education, whereby the educated people preferred high quality products over low quality, while those with less or no education didn't consider qualityas an important parameter to consider. About 58\% of the city's population is occupied by the low level and uneducated civilians. 


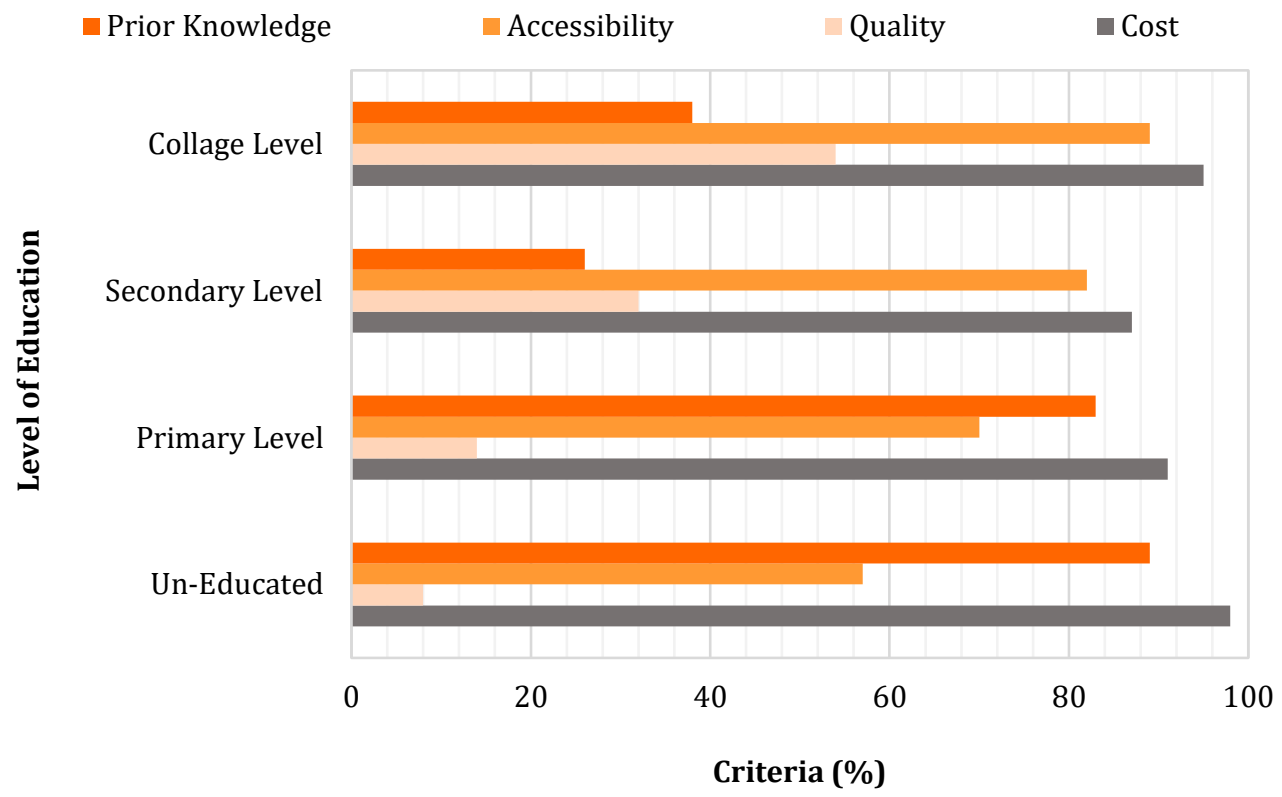

FIGURE 4: Selection criteria of EEE by Dar es Salaam cities residents

Based on questionnaire findings from the public, on average a person uses a phone for a maximum of two years before it dies. It should be remembered that all the working force in Dar es Salaam own at least one phone, with others having up to three phones at once. This being the case in near future the generation of WEEE, especially the mobile phones and accessories will be higher than before. In two years', time at least two in three houses, will have unused mobile phones and accessories as waste, because about $35 \%$ of the Dar es Salaam population keep the WEEE at home, especially the phones and accessories.
They don't want to dump them or sell them, because they consider them as valuable materials even though they are of no use at all. Also, $30 \%$ of the population opt to give away the barely dead phone to close people of their contact as gifts, while $11 \%$ sell them to informal buyers with either cash or exchange terms depending with the condition of the EEE. The remaining 24\% dump them with other solid waste, where the waste is collected and dumped to Pugu landfill (FIGURE 5)

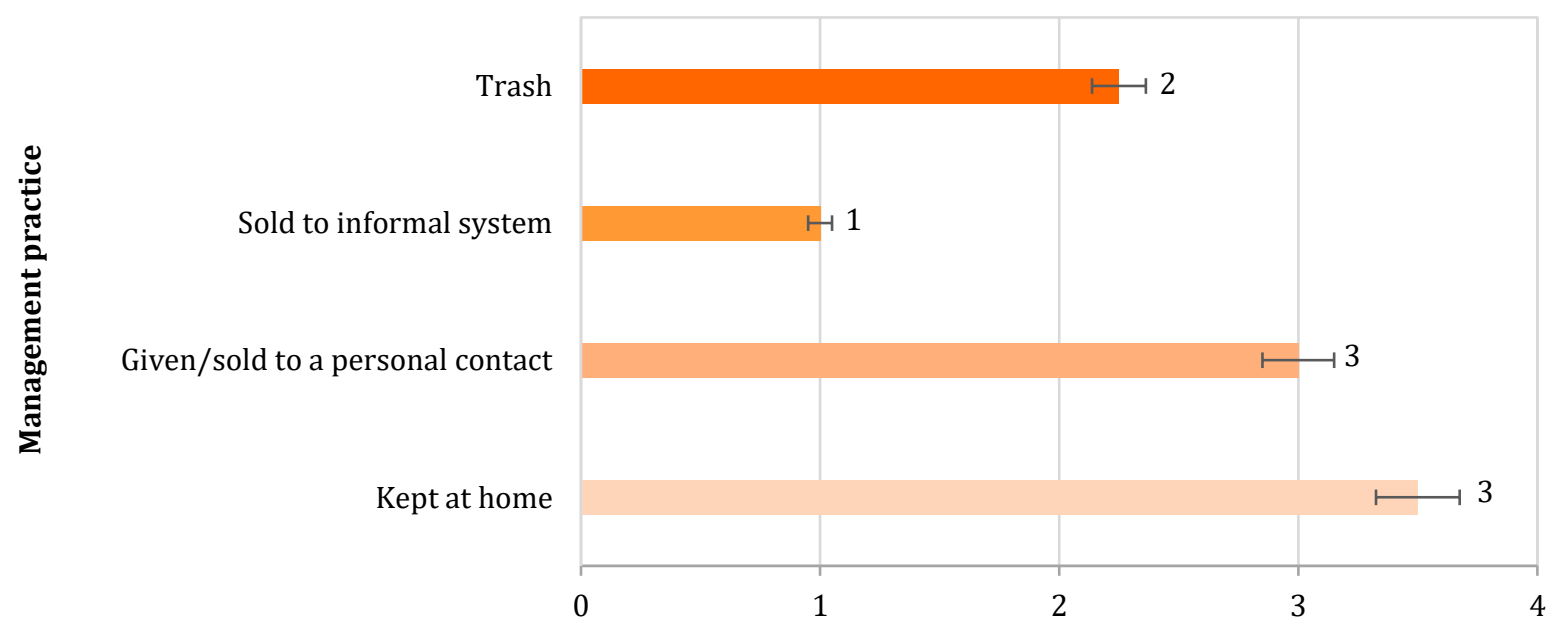

Population representation (\%)

FIGURE 5: WEEE management at household level in Dar es Salaam city

About $80 \%$ of the EEE sellers in Dar es Salaam city don't know the Extended Producer Responsibility principle (EPR) as stated by NBS and UNU, (2019) and URT (2009), that the producer is reliable of taking care of the generated by its EEE $[11,36,37,38]$. Even the $20 \%$ who knows about the principle still can't take the WEEE back to manufacturers due to cost implications and complications that may arise like bureaucracy and alike. That being the case $80 \%$ of the sellers don't offer warranty cards, on the other hand the remaining $20 \%$ provides warranty cards because they are aware that the supplier or manufacturer is the responsible one for the damage due to malfunctioning and alike that doesn't involve the bad habit of user.

Surprisingly only the $24 \%$ of public in Dar es Salaam city considers the EEE as waste after it has been broken and can't be used anymore, even when they don't have any option, even when they dump them, they dump with heartfelt pain of losing valuable material. The WEEE waste consideration is well explained by FIGURE 6 . 


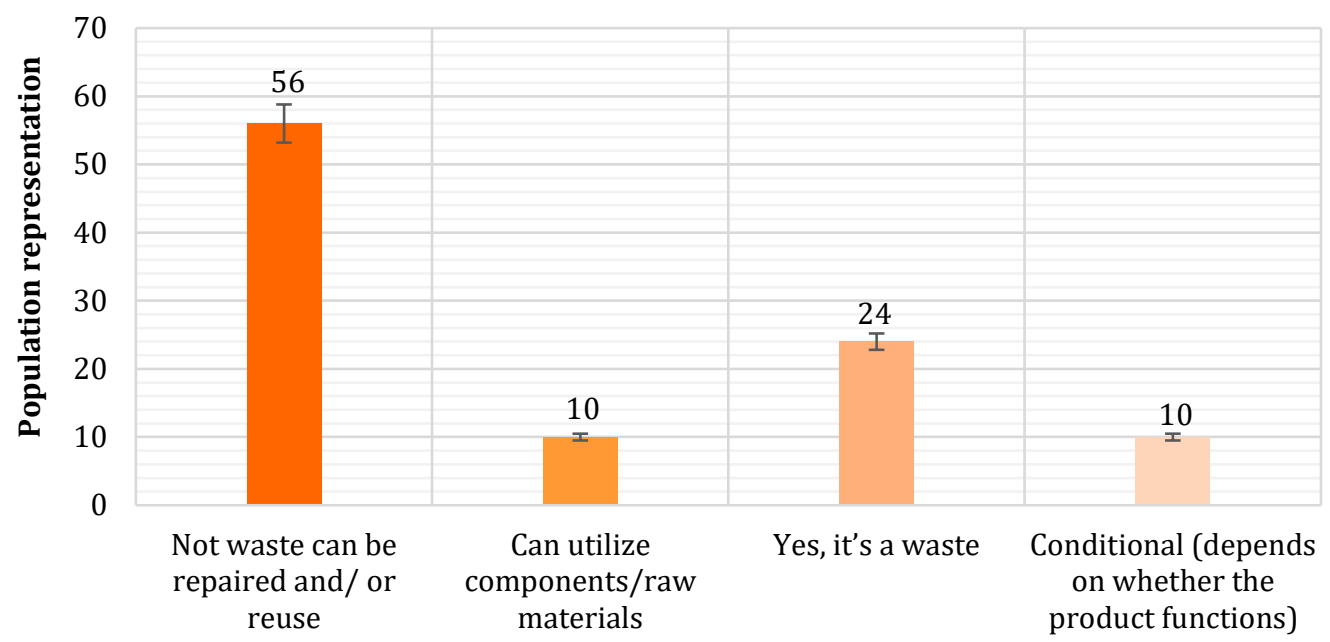

Views on WEEE

FIGURE 6: Public views on WEEE

Since majority of the public including the EEE repair technicians considering the WEEE as valuable materials even though they are dead, blind their thinking towards effects of the WEEE to them and the environment. The WEEE contains hazardous chemicals and materials such as Lead ( $\mathrm{Pb})$, Cadmium (Cd), Beryllium (Be), or Brominated flame retardants. Yet, the about $79 \%$ of Dar es Salaam residents are not aware of these consequences, as a result they might be exposed directly or indirectly to these cancerogenic effects $[26,27,28]$. The WEEE can be collected by the municipal or recycler Enterprises and be treated for re-use, recycle or safe disposal $[15,17,18,19,20$, $26,44]$. But, about $76 \%$ of residents and technicians doesn't know of the presence of recyclers, while only $24 \%$ are aware of the presence of recyclers.
The majority who are not aware of the recyclers companies they just know that the waste is collected by municipal solid waste trucks or contracted companies to the landfill where it is dumped. This means that majority of the residents are not aware that the waste can be sold to recyclers.

\section{Current and future trends of WEEE management in Dar es Salaam}

In order to get the trend information, utilization of past records wasinevitable. The EEE and WEEE information for Dar es Salaam is currently not available, so the 20 years records on country wise has been adopted to observe the trend. According to NBS and UNU (2019), the importation of E- equipments is increasing with years within Tanzania Mainland [11] (FIGURE 7).

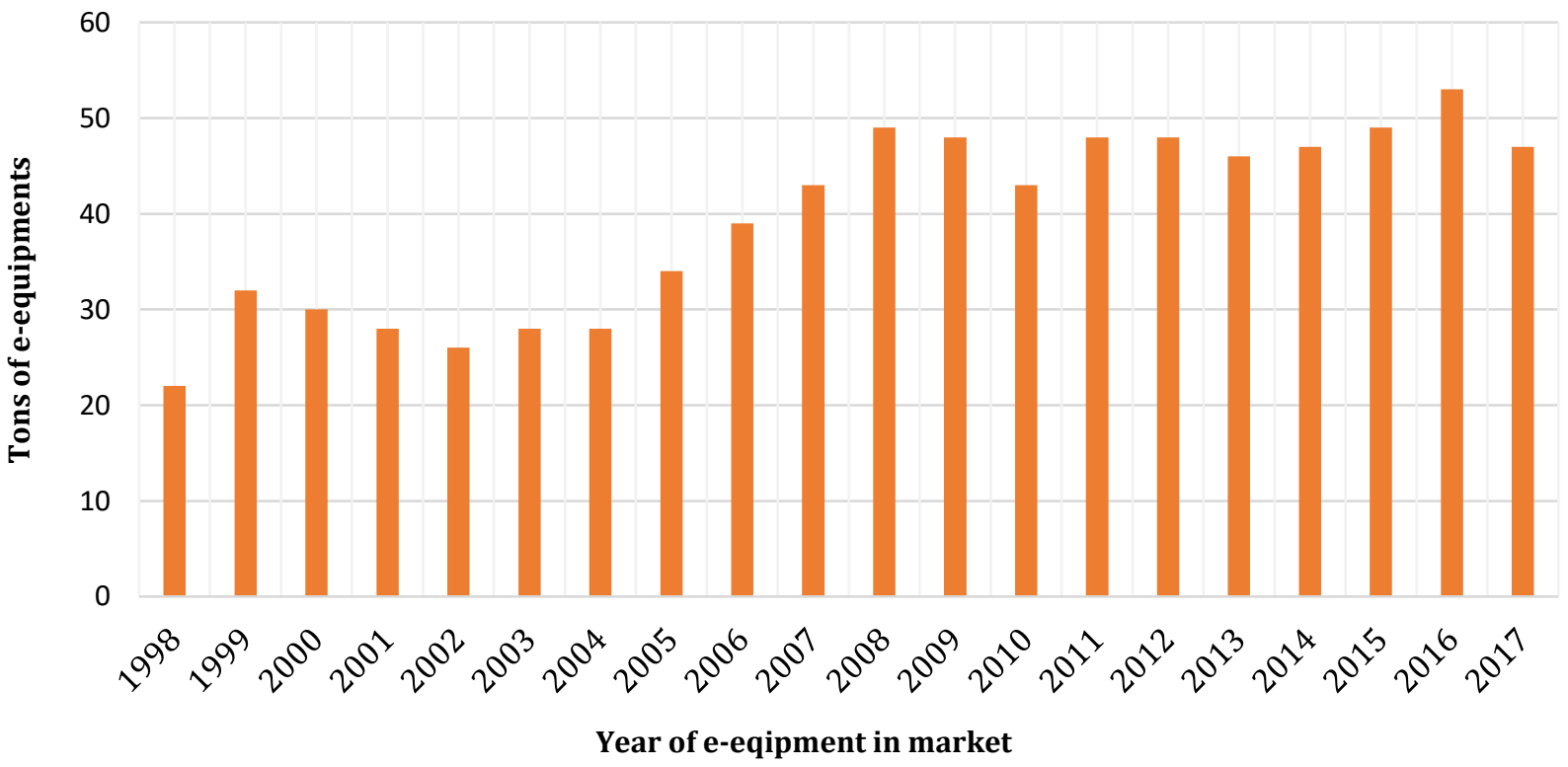

FIGURE 7: Electrical and Electronics equipments put on market between 1998 to 2017 Source: NBS and UNU (2019).

The information in FIGURE 6, implies that the increase in economic growth rate of the nation together with population growth rate and the household purchasing capacity triggers the increase in E-equipment importation/put on market, because the Nation has been increasing in population and GDP.
Also, the increase in E-equipment importation leads to increase in E-waste, that why the E-waste generation rate was found to increase with increasing time from 1998 to 2017 (FIGURE 8). 


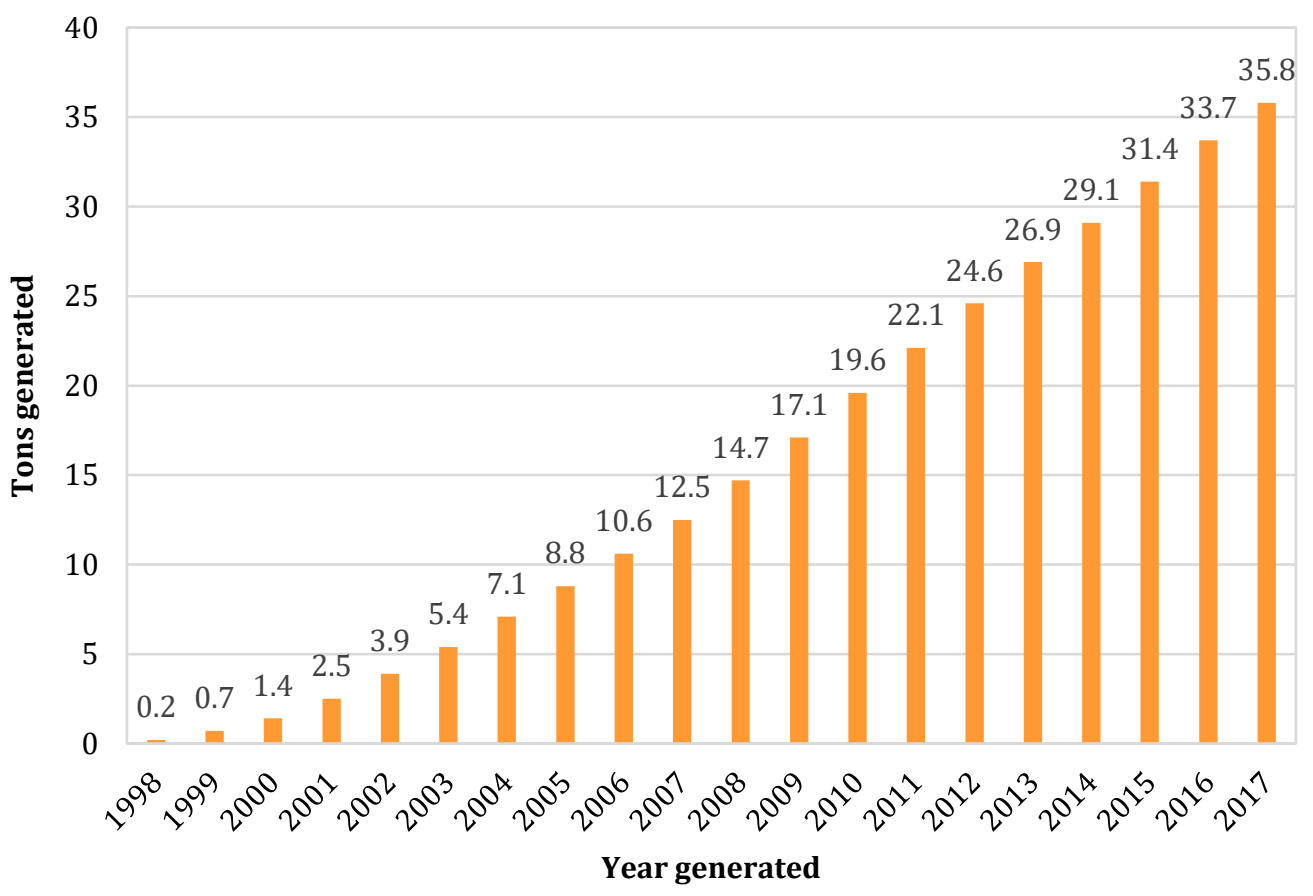

FIGURE 8: Electrical and Electronic wastes generated between 1998 to 2017 Source: NBS and UNU (2019).

The increase in WEEE in FIGURE 7, is thought to be due to unlimited available number of recyclers and exportation of expired or broken EEE to manufacturers who are not in Tanzania. About $87 \%$ of the EEE are from china and the remaining 13\% comes from Europe, America and United Arabs States. So, drivers that trigger availability of EEE like; increase in economic rate, population growth rate and household purchasing capacity favors generation potential of waste, while the reduction of waste is favored by the reducing drivers like; recycling and exportation of waste to manufacturers. Phone and accessors are the leading EEE imported and put to markets within Dar es Salaam city.

This means that Dar es Salaam and Tanzania at large is liable of handling the E-Waste generated by other countries. At least there should be liability cost for waste management or else the manufacturer should be liable of handling the waste produced. Also, surveys showed that averagely about $36 \%(\mathrm{hpc}=36)$ of households have purchasing capacity of EEE. The study also found out that there is no dealer that is considered as exporter of WEEE to manufacturer (wer $=0$ ), but rather they are considered as recyclers, who can recycle about $35 \%$ of the waste generated ( $\mathrm{rr}=35)$. Now plugging the values to the equation of estimating the discarded waste, it was found out that by five (5) years from now (2026), the amount of discarded WEEE will be $68 \%$ of the generated, provided that the management intervention doesn't chance. This means more than half of the EEE imported will end up as WEEE, as a result the natural environment and human health shall be in danger $[1,30,31,32,33,37]$.

According to the Mr. Chilambo (Dealers representor), the business has been seriously affected by COVID-19, because most of the borders where they export their products to were closed, as a result the business destabilized. Most of the WEEE dealers reduced the collection rate as a result the overall collection is thought to be reduced. This signifies that the business can be affected by national and international calamities/disasters like COVID-19. For example, the lithium ion batteries can't be recycled within Tanzania or any country within Tanzania but can be transported to Europe for recycling, so the COVID-19 hindered transportation hence making the stoke too big (FIGURE 9).
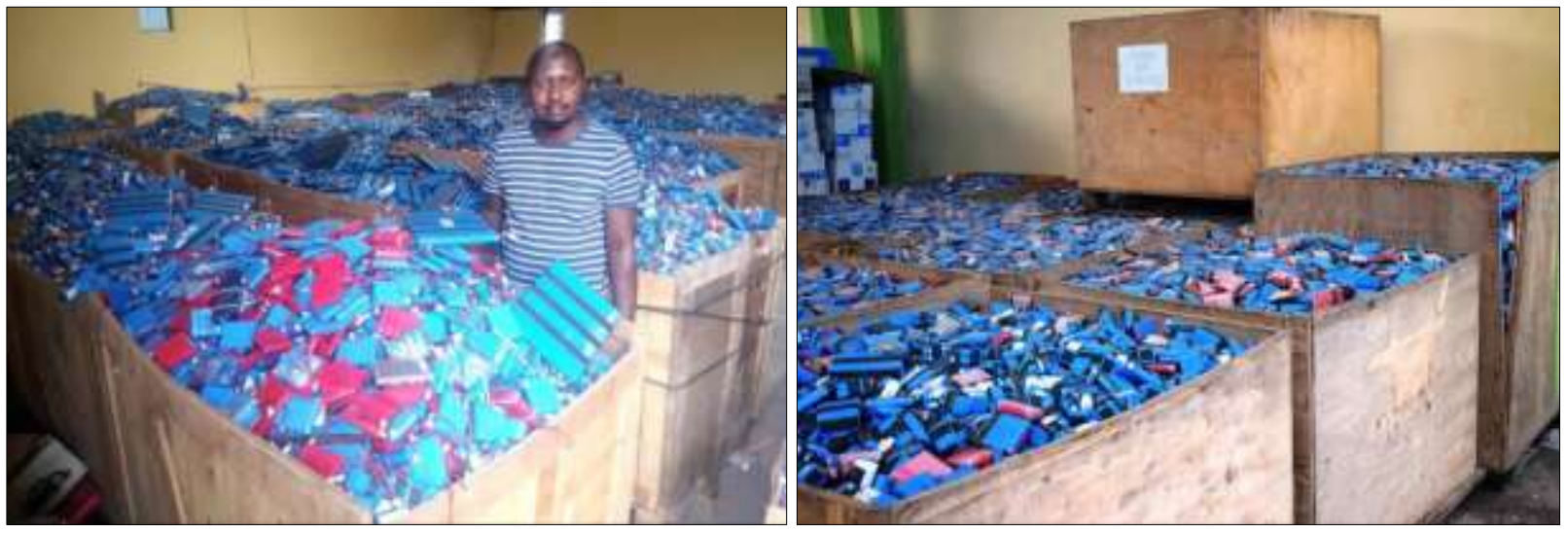

FIGURE 9: Piling of lithium ion batteries at Chilambo general trade company LTD due to COVID-19.

Also, the printed circuits are supposed to exported to Belgium, Germany, Switzerland and America but the COVID19 interfered the business hence contributing much to generation of waste.
This implies that the dealers have high contribution on WEEE on the environment within Dar es Salaam city. 


\section{CONCLUSIONS AND RECOMMENDATIONS}

\section{Conclusions}

Waste Electrical and Electronic Equipments is an alarming challenge that requires urgent attention in Dar es Salaam city because all working force of the city owns at least one mobile phone and accessories with an average life span of two years. The demand in computer accessories and home appliances is also alarming. In 2026 it is projected that about $68 \%$ of the generated WEEE in the city will end up either being discarded to the environment or at homes (households). The public is not aware of the effects that may rise from WEEE, as a result they are exposed to cancerogenic environments. The current available recycling companies are insufficient to solve the problem of WEEE as they can totally handle only the $35 \%$ of the generated WEEE.

\section{Recommendations}

The ministry of Vice Presidents Office, environmental division (VPO- Environment) should work closely with the registered and unregistered WEEE recyclers to point out the obstacles in the recycling business and set a way forward on adequate sustainable solutions. Among issues calling for urgent solutions is the wave in registration and certification costs to recyclers and reduction in bureaucracy to people/companies intending to join the WEEE recycling business.

\section{ACKNOWLEDGEMENT}

This work was part of the scholarship offered to Mr. Nyabise Nelson by the Ministry of Commerce of People's Republic of China (MOFCOM) to facilitate his master of Environmental Science and Engineering at the College of Environmental Science and Engineering, Tongji University, China. Tongji University, Ardhi University, especially the School of Environmental Science and Technology (SEST) and the Principled Entrepreneurship and Innovations (PEI Enterprises) are highly appreciated for their technical and moral support.

\section{DATA AVAILABILITY STATEMENT}

All relevant data are available as supplementary information if needed.

\section{REFERENCES}

[1] Awasthi, A., Cucchiella, F., D'Adamo, I., Li, J., Rosa, P., Terzi, S. and Wei, G. (2018). Modelling the correlations of e-waste quantity with economic increase. Science of The Total Environment. 613-614. 46-53. DOI: 10.1016/j.scitotenv.2017.08.288.

[2] Baldé, C.P., Forti V., Gray, V., Kuehr, R. and Stegmann, P. (2017). The Global E-waste Monitor - 2017, United Nations University (UNU), International Telecommunication Union (ITU) \& International Solid Waste Association (ISWA), Bonn/Geneva/Vienna. p. 978-92.

[3] Borthakur, A. and Govind, M. (2017). Conservation, and Recycling, Emerging trends in consumers' Ewaste disposal behaviour and awareness: A worldwide overview with special focus on India. 117: p. 102-113.

[4] Di Maio, F., Rem, P.C., Baldé, C.P. and Polder, M. (2017). Measuring resource efficiency and circular economy: A market value approach. 122: p. 163-171.

[5] Fernández, Y., Río, J., Rodríguez-Iglesias, J., Castrillon, L. and Marañon, E. (2014). Life cycle assessment of different municipal solid waste management options: A case study of Asturias (Spain). Journal of Cleaner Production. 81. 178-189. DOI: 10.1016/j.jclepro.2014.06.008.
[6] Herat, S. (2007). Air, Water, Sustainable management of electronic waste (e-waste). 35(4): p.305-310.

[7] Kumar, V., Bee, D.J., Shirodkar, P.S., Tumkor, S.T., Bettig, B.P. and Sutherland,J.W. (2005). Towards sustainable "product and material flow" cycles: identifying barriers to achieving product multi-use and zero waste in ASME 2005. International Mechanical Engineering Congress and Exposition. American Society of Mechanical Engineers Digital Collection.

[8] Kumar, V., Garg, R., Rahman, Z. and Kazmi, A.A (2011). Sustainability and E-waste management scenario in India.

[9] Long, E., Kokke, S., Lundie, D., Shaw, N., Ijomah, W. and Kao, C. (2016). Technical solutions to improve global sustainable management of waste electrical and electronic equipment (WEEE) in the EU and China. Journal of Remanufacturing. 6. DOI: 10.1186/s13243-015-0023-6.

[10] Mateus, M. and Campuzano, F. (2008). The DPSIR framework applied to the integrated management of coastal areas. DOI: 10.13140/2.1.3841.6960.

[11] National Bureau of Statistics and United Nations University, ViE - SCYCLE (2019). National E-Waste Statistics Report 2019. National Bureau Statistics, Dodoma, Tanzania, United Nations University, ViE SCYCLE, Bonn, Germany.

[12] NBS (2018). Population projection 2018. NBS newsletter. Issue No. 33

[13] NBS and CGS (2013). 2012 Population and Housing census. http:

www.nbs.go.tz/takwimu/references/Tanzania_Tanza nia_in_figures2012.pdf (cited on 2nd August 2015).

[14] Nnorom, I.C. and Osibanjo, O.J.R. (2008). Conservation and recycling, Overview of electronic waste (e-waste) management practices and legislations, and their poor applications in the developing countries. 52(6): p. 843-858.

[15] OECD. (2008). Annual report 2008.

[16] Ongondo, F.O., Williams, I.D. and Cherrett, T.J. (2011). How are WEEE doing? A global review of the management of electrical and electronic wastes. 31(4): p. 714-730.

[17] Osibanjo, O. and Nnorom, I.M. (2007). The challenge of electronic waste (e-waste) management in developing countries. 25(6): p. 489-501.

[18] Pariatamby, A., and Victor, D.J. (2013). Policy trends of e-waste management in Asia. 15(4): p. 411-419.

[19] Pathak, P., Srivastava, R.R. and Ojasvi. (2017). Assessment of legislation and practices for the sustainable management of waste electrical and electronic equipment in India, Renewable and Sustainable Energy Reviews, Elsevier, vol. 78(C), pages 220-232.

[20] Prakash, S., Manhart, A., and Agyekum, O. (2010). Socio-economic assessment and feasibility study on sustainable e-waste management in Ghana 
[21] Ray, S.J. (2013). Green software engineering process: moving towards sustainable software product design. 4(1): p. 25-29.

[22] Robinson, B.H. (2009). E-waste: an assessment of global production and environmental impacts. 408(2): p. 183-191.

[23] Schiffer, E. and J. Peakes. (2009). An innovative approach to building stronger coalitions: The NetMap Toolbox. Development in Practice. 19(1): p. 103-105.

[24] Schluep, M. (2010). E-Waste Management in Developing Countries-with a focus on Africa. in ITU Symposium on ICTs and the Environment \& Climate Change.

[25] Schmidt, C.W. (2006). Unfair trade e-waste in Africa. National Institute of Environmental Health Sciences.

[26] Shenoy, S.S. and Eeratta, R. (2011). Green software development model: An approach towards sustainable software development in 2011. Annual IEEE India Conference.

[27] Shumon, M.R.H., Ahmed, S. and Islam, M.T. (2014). Electronic waste: present status and future perspectives of sustainable management practices in Malaysia. 72(7): p. 2239-2249.

[28] Song Q., Wang Z., Li J., and Zeng X. (2013). The life cycle assessment of an e-waste treatment enterprise in China. Journal of Material Cycles and Waste Management,15(4),469.

[29] Souza, Ricardo Gabbay de et al., (2016). Sustainability assessment and prioritization of ewaste management options in Brazil. Waste Management. Oxford: Pergamon-elsevier Science Ltd, v. 57, p. 46-56.

[30] Sperry, R.C. and Jetter, A.J. (2019). A systems approach to project stakeholder management: fuzzy cognitive map modeling. Project management journal. 50(6): p. 699-715.

[31] Suárez-Cebador, M., Carlos Rubio-Romero, J., López-Toro, A., and Arjona-Jiménez, R. (2017). Stakeholder Analysis of Municipal Solid Waste Companies-a First Step Towards Successful Corporate Social Responsibility. Journal of Environmental Science and Management 20-2:4053. ISSN 0119-1144.

[32] Suryawanshi, K. and Narkhede. S. (2013). Green ICT implementation at educational institution: A step towards sustainable future in 2013 IEEE International Conference in MOOC, Innovation and Technology in Education (MITE).

[33] U.S. Environmental Protection Agency (2016). Electronic Products Generation and Recycling Methodology Review. U.S. Environmental Protection Agency.
[34] UNEP. (2007). E-waste Volume II: E-waste Management Manual

[35] UNIDO (2011). e-Waste Assessment Tanzania UNIDO e-waste initiative for Tanzania. Presented by: Anne Magashi, A. and Schluep, M.

[36] United Republic of Tanzania. Vice Presidents Office. Division of Environment. Guidelines for Management of Hazardous Waste. June 2013, p. 12.

[37] URT, (2004). Environmental Management Act No. 20 of 2004.

[38] URT, (2009). Environmental management (Hazardous waste control regulation of 2009 and its amendment of 2018).

[39] URT, (2018). Environmental Annual fees and charges regulation, 2018.

[40] URT, (2019). National E-waste statistics report, 2019, Tanzania Mainland.

[41] Wang, F., Huisman, J. and Meskers, C.E. (2012). The Best of 2 Worlds philosophy: developing local dismantling and global infrastructure network for sustainable e-waste treatment in emerging economies. Waste Management. New York. 32(11):2134-2146.

DOI: $10.1016 /$ j.wasman.2012.03.029.

[42] Wath, S., Vaidya, A., Dutt, P. and Chakrabarti, T. (2010). A roadmap for development of sustainable E-waste management system in India. The Science of the total environment. 409. 19-32. DOI: 10.1016/j.scitotenv.2010.09.030

[43] Wilson, D.C. (2007). Development drivers for waste management. 25(3): p. 198-207.

[44] Xia, K., Gao, L., Chao, K.M., and Wang, L. (2015). A Cloud-based Disassembly Planning Approach towards Sustainable Management of WEEE. In 2015 IEEE 12TH INTERNATIONAL CONFERENCE ON E-BUSINESS ENGINEERING (ICEBE) (pp. 203208).

[45] Zeng, X., Duan, H., Wang, F. and Li, J. (2017). Examining environmental management of e- waste: China's experience and lessons, Renewable and Sustainable Energy Reviews, Elsevier, vol. 72(C), pages 1076-1082. DOI: 10.1016/j.rser.2016.10.015. 